\title{
NEED FOR FACILITATING INNOVATION AND RESEARCH
}

\section{Dear Reader,}

Introspection and open debates are called for in the current context of the clarion call for innovation in pharmaceuticals, biotechnology, diagnostics and preventive healthcare. The Indian pharmaceutical industry is lagging behind in the global innovation index as well as in all forms of research and innovation. India is known as a source of qualified technical human resources. However, the quality of this resource is far inferior and often appears unfit for the higher echelons of innovative research. Who is to blame? The quality standards of education in many of the Indian Universities are relatively mediocre, to put it softly. Indian universities do not figure in the top 200 universities of the world. The Indian student community is not to be blamed for this

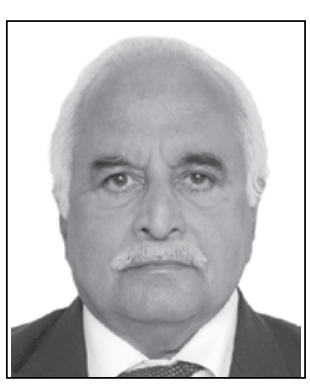
pathetic state. Over the years, the Indian education system has de-emphasized the objective of knowledge acquisition and all-round development of the student as the goal of education. Education in Indian universities generally concentrate on training for employment and nothing more. Higher learning objectives have been diluted over the last few generations, so much so, that many of the current crop of teachers, professors and research scientists are themselves falling short of needful training and teaching skills. The student community has become the victim of the mediocre quality of teaching faculty. Therefore, it is imperative that the Indian educational system and infrastructure should emphasize more intensively on "training the trainers" and helping the teaching community to "learn, unlearn and relearn" to meet the growing demands on upgrading the quality of Indian education. In these times of ongoing disputes and debates on language education, it is indeed shocking to observe the poor English language skills of highly "qualified" doctorates and researchers. The agencies and organizations responsible for the quality of education in India should wake up now or it will be too late.

Traditional industrial and research practices are being increasingly challenged in the current internet age of artificial intelligence, genetic engineering, big data management, cloud computing and increasing attention to disruptive innovations. The Indian Pharmaceutical industry which is substantially driven by small-medium enterprises and entrepreneurs, need to take note and join the innovation band-wagon which is receiving the clarion call not only in India but globally. To remain relevant, participating in innovative research for progress and growth has become imperative. Recognising the role of small medium enterprises in innovation and research, the Government of India has announced a proposal for substantial fee reduction for filing patent applications for MSMEs (published in IDMA Bulletin, 21st September 2019, page 40 ). Further, the Patent Rules have been amended on $17^{\text {th }}$ September 2019, granting further exemptions for sectors including MSMEs. While the proposal should be received by the pharmaceutical industry with open arms, much more needs to be done to encourage the MSME sector of the Indian pharmaceutical industry to become an active participant in innovative research and patenting. Indian pharma MSMEs are yet to master the art of partnering with each other in co-development and IP-sharing, which is very prevalent overseas. Pharma MSMEs need to also become active in developing $R \& D$ alliances with pharmacy colleges, universities and research institutes. The academic institutions are equally to blame for not partnering with the MSME sector of the Indian Pharmaceutical industry who needs partnering for research more than the corporate giants in the pharma industry. Proposals like reduction in patent filing fees, in isolation, will not help boosting innovation. There needs to be an all-round review and positive initiatives in tandem are required to boost research and innovation.

A major hurdle for the MSME pharma sector to engage R\&D and innovation is continuing hassles in "ease of doing business". The MSMEs find it hard to avail of the incentives or rebates granted on paper due to procedural issues. MSME entrepreneurs are compelled to waste precious time, money and attention pursuing frivolous court cases initiated by hyperactive drug inspectors on frivolous or often fictitious quality claims. While the central drug regulators (CDSCO and DCGI) are substantially upscaling their establishment and regulatory environment, the State Regulators, except Maharashtra and Gujarat, need to put their house in order. Indian pharmaceutical industry in general, more particularly the API manufacturers and MSME sector have not yet received the benefits of the "ease of doing business" proposals. There is need to reign in negative minded Drug Inspectors to stop them from filing frivolous, often fabricated litigations against 
pharma entrepreneurs, so that they can fruitfully engage in positive activities such as innovation and inventive R\&D initiatives. Direct and indirect tax incentives need to be enhanced by way of tax rebates to encourage innovation and drug research. Industry-Academia collaborations need also to be rewarded through incentives and rebates.

Indian MSMEs in the pharmaceutical industry jointly with academic partners should increasingly pursue potential cross border research alliances with pharmaceutical industries in emerging economies such as Turkey, Egypt, Philippines, Malaysia, Thailand, Indonesia, Brazil, Argentina, Mexico, Cuba and others. While developed countries such as USA, European member states and Japan are natural allies of larger Indian pharma companies, MSME can seek alliances for research and innovation with similar size pharma companies in countries such as South Korea, Israel, Australia and New Zealand. In short, MSMEs need to board the innovation band-wagon sooner or later, the earlier the better not only for survival in the long term, but also to emerge from the routine traditional mind-sets.

Coming back to the title of Innovation, the lawmakers in their own wisdom (or lack of it) made the "Fundamental Duties" under Constitution of India, optional and not compulsory. Article 51A of Indian Constitution is worth visiting. It is indeed a masterpiece for building the Nation. "To develop scientific temper" and "spirit of enquiry" among others are enshrined in the Indian Constitution. In line with this, we need to incorporate these elements into grassroot level onwards to revamp Indian education. Innovation and its components must be introduced in school curriculums. Teachers must be taught and trained on the basics of "spirit of enquiry" and "scientific temper". In current context, "Innovation" has acquired "global tsunami" proportions. Many overseas Indians have become participants in these breakthrough and disruptive innovations. Recently, Sundar Pichai (an Indian alumni of IIT, Madras, IIT Kharagpur and later Stanford and Wharton) had presented Google's breakthrough innovations in healthcare, wherein he disclosed that Google can now use Al (Artificial Intelligence) to predict risks of medical events simply by analysing "Retino Scans" and predict adverse cardiovascular risks for next 5 years. "Diabetic Retinopathy" studies are in advanced stage for prevention and cure using Al by Google. Healthcare has become the fiefdom of many more players in diverse fields such as IT, Al and others. It is therefore essential for Indian pharmaceutical, biotech and healthcare researchers to "unlearn" the traditional approaches and "relearn" about working together and "networking" with other field experts to create a 'research loop' for the innovation system for the future. It is now or never. Let us wake up and "innovate" as a team and as a Nation.

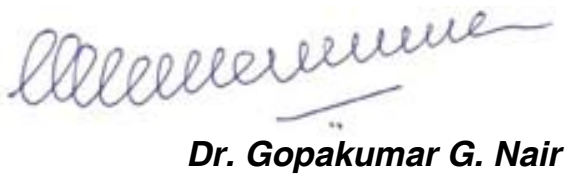

https://doi.org/10.53879/id.56.09.p0005

Editor,

Indian Drugs

\section{About the Editor}

Dr. Gopakumar G. Nair is a Ph.D in Organic Chemistry (1966) from National Chemical Laboratory, Pune (Pune University). He was a Post-Doctoral fellow at IIT Bombay, Powai (1967) before joining the Pharma Industry. He was Director of Bombay Drug House P. Ltd., later Chairman of BDH Industries Ltd. as well as CMD of Bombay Drugs \& Pharma Ltd., which was merged with Strides Arcolab Ltd. in 2001. Dr. Nair served IDMA as office bearer for many years from 1972 onwards and was Chairman of various Committees for nearly 4 decades. He was the President of IDMA in 1999/2000. Currently, Dr. Nair is the Chairman of the IPR Committee in IDMA.

Having moved into the Intellectual Property field, he was the Dean of IIPS (Institute of Intellectual Property Studies) at Hyderabad in 2001/2002. Later, he set up his own boutique IP firm, Gopakumar Nair Associates, as well as Gnanlex Hermeneutics Pvt. Ltd., having done his L. L. B. from Mumbai University. He is also CEO of Patent Gurukul and President of Bharat Education Society, Kurla, Mumbai, managing many educational institutions in and around Mumbai.

If you would like to comment on the editorial please write to us at publications@idmaindia.com 